\title{
An ecological connectivity network maintains genetic diversity of a flagship wildflower, Pulsatilla vulgaris
}

\section{DiLeo, Michelle F.}

2017-08

DiLeo , M F , Rico , Y , Boehmer , H J \& Wagner , H H 2017 , ' An ecological connectivity network maintains genetic diversity of a flagship wildflower, Pulsatilla vulgaris ' , Biological Conservation, vol. 212 , pp. 12-21 . https://doi.org/10.1016/j.biocon.2017.05.026

http://hdl.handle.net/10138/304105

https://doi.org/10.1016/j.biocon.2017.05.026

cc_by_nc_nd

acceptedVersion

Downloaded from Helda, University of Helsinki institutional repository.

This is an electronic reprint of the original article.

This reprint may differ from the original in pagination and typographic detail.

Please cite the original version. 
1 An ecological connectivity network maintains genetic diversity of a flagship wildflower,

2 Pulsatilla vulgaris

3 Michelle F. DiLeo ${ }^{1,2^{*}}$, Yessica Rico ${ }^{3}$, Hans Juergen Boehmer ${ }^{4}$, and Helene H. Wagner ${ }^{1}$

41 -Department of Biology, University of Toronto Mississauga, 3359 Mississauga Road,

5 Mississauga ON, L5L 1C6

62 - Metapopulation Research Centre, Faculty of Biological and Environmental Sciences,

7 University of Helsinki, PO Box 65, 00014 University of Helsinki, Finland

83 - CONACYT, Instituto de Ecología A.C. Centro Regional del Bajío, 253 Pátzcuaro

9 Michoacán, 61600 México.

104 -School of Geography, Earth Science and Environment, University of the South Pacific, Suva,

11 Fiji Islands

$12 *$ corresponding author: michelle.dileo@gmail.com; +358 0417574836

13

14 Keywords: actual functional connectivity, calcareous grassland, ecological networks, fitness,

15 fragmentation, genetic diversity, landscape genetics, microsatellites, Pulsatilla vulgaris 


\section{Abstract}

17 Ecological connectivity networks have been proposed as an efficient way to reconnect

18 communities in fragmented landscapes. Yet few studies have evaluated if they are successful at

19 enhancing actual functional connectivity (i.e. realized dispersal or gene flow) of focal species, or

20 if this enhanced connectivity is enough to maintain genetic diversity and fitness of plant

21 populations. Here we test the efficacy of an ecological connectivity network implemented in

22 southern Germany since 1989 to reconnect calcareous grassland fragments through rotational

23 shepherding. We genotyped 1,449 individuals from 57 populations and measured fitness-related

24 traits in 10 populations of Pulsatilla vulgaris, a flagship species of calcareous grasslands in

25 Europe. We tested if the shepherding network explained functional connectivity in P. vulgaris

26 and if higher connectivity translated to higher genetic diversity and fitness of populations. We

27 found that population-specific $\mathrm{F}_{\text {st }}$ was lowest in populations that had high connectivity within the

28 shepherding network, and that well-connected populations within the network had significantly

29 higher genetic diversity than ungrazed and more isolated grazed populations. Moreover, genetic

30 diversity was significantly positively correlated with both seed set and seed mass. Together our

31 results suggest that the implementation of an ecological shepherding network is an effective

32 management measure to maintain functional connectivity and genetic diversity at the landscape

33 scale for a calcareous grassland specialist. Populations with reduced genetic diversity would

34 likely benefit from inclusion, or better integration into the ecological connectivity network. Our

35 study demonstrates the often postulated but rarely tested sequence of positive associations

36 between connectivity, genetic diversity, and fitness at the landscape scale, and provides a

37 framework for testing the efficacy of ecological connectivity networks for focal species using

38 molecular genetic tools. 


\section{Introduction}

40 Habitat loss and fragmentation are major threats to the persistence of populations across nearly

41 all taxonomic groups (Fischer and Lindenmayer 2007). Together, these processes can lead to

42 reductions in effective population size and gene flow among previously contiguous patches,

43 enhancing the effects of genetic drift in small populations and accelerating the loss of genetic

44 diversity (Frankham 2005; Reed and Frankham 2003). Small and isolated populations are more

45 prone to inbreeding depression and suffer a reduced potential for adaptation (Frankham 2005).

46 Preserving genetic diversity is not only important for the population or species at-hand, but also

47 plays a critical role in the functioning of communities and ecosystems, with positive influences

48 on species diversity, disease dynamics, food-web dynamics, and ecosystem cycling (Hughes et

49 al. 2008; Johnson et al. 2006; Lamy et al. 2013).

50 Ecological connectivity networks (i.e. sets of connected suitable habitats that allow

51 persistence of viable metapopulations for multiple species in a community), are increasingly

52 being implemented to restore dispersal linkages between remnant patches in fragmented

53 landscapes (Baguette et al. 2013; Boitani et al. 2007; Gilbert-Norton et al. 2010; Maiorano et al.

54 2015; Whitelaw and Eagles 2007). Dispersal linkages are often structural features of the

55 landscape, such as habitat corridors or stepping-stones that are created, protected, or maintained

56 under the assumption that they directly support the movement of organisms and their genes,

57 between fragments (known as functional connectivity). For plants, an alternative strategy to

58 reconnect populations exists where vectors of seed or pollen dispersal, instead of structural

59 aspects of the landscape, are restored for focal species. For example, rotational shepherding has

60 the potential to disperse seeds over very long distances (e.g. >100 km; Fischer et al. 1996; 
61 Manzano and Malo 2006) and has been used as a strategy to reconnect grassland plant

62 populations in central Europe (Auffret et al. 2012; Butaye et al. 2005).

63 The spatial extent of ecological connectivity networks and their large number of corridors

64 often preclude the collection of base-line connectivity data to help inform decisions about the

65 suitability of linkages for protection. Most often, ecological connectivity networks are designed

66 solely based on the structural connectivity of the landscape (Cushman et al. 2009). More

67 recently, conservation managers have considered potential functional connectivity when

68 designing networks, using dispersal thresholds of focal species to select linkages for protection

69 (e.g. Bruinderink et al. 2003; Carroll et al. 2012; Cushman et al. 2009). However, it is rarely

70 tested if ecological connectivity networks are successful at maintaining actual functional

71 connectivity (i.e. realized dispersal or gene flow, Calabrese and Fagan 2004, but see Melles et al.

72 2012), or test if the enhanced connectivity provided by the network is enough to maintain genetic

73 diversity of populations. Consequently, there is a great need to evaluate the utility of ecological

74 connectivity networks for supporting functional connectivity for focal species and communities

75 (Boitani et al. 2007). Neutral genetic diversity on its own may not be a suitable conservation

76 target as the argument to conserve diversity is made on the basis of its presumed association with

77 fitness and potential for adaptation; for selectively neutral markers this evidence is equivocal

78 across the plant world (Leimu et al. 2006). Thus a better evaluation of the outcomes of

79 conservation planning involves applied targets such as fitness components or a demonstrated link

80 between diversity and fitness.

81 Here we tested the efficacy of an ecological connectivity network implemented in

82 southern Germany since 1989 to reconnect abandoned calcareous grassland fragments through

83 rotational shepherding. We measured genetic differentiation, genetic diversity and fitness-related 
84 traits in the perennial wildflower Pulsatilla vulgaris Mill. (Ranunculaceae)- a flagship and

85 specialist species of calcareous grasslands in Europe and one of high conservation concern

86 (IUCN 2015). We tested the hypothesis that the shepherding network maintains seed dispersal

87 and thus gene flow of populations, and that this enhanced gene flow translates to higher genetic

88 diversity and fitness. Previous ecological research in this system showed that shepherding

89 connectivity is associated with increased species richness (Wagner et al. 2013), patch

90 colonization rates (Rico et al. 2012) and patch occupancy (Rico et al. 2014a) of characteristic

91 calcareous grassland plants. At the molecular level, research on a single species, Dianthus

92 carthusianorum, indicated that shepherding decreased genetic divergence among connected

93 populations (Rico et al. 2014b), and increased within-population neutral genetic diversity (Rico

94 et al. 2014a). The question that remains is whether such an increase in genetic diversity is

95 enough to make an impact on the fitness of populations, specifically for species of concern such

96 as $P$. vulgaris. We ask: (1) Does the shepherding network explain gene flow among $P$. vulgaris

97 populations, as quantified by population-specific genetic differentiation? (2) Does the potential

98 enhanced gene flow provided by the shepherding network translate to higher genetic diversity in

99 connected populations? (3) Does higher genetic diversity translate to higher fitness in this

100 system, beyond the effect of population size? This system is ideal as it allows us to compare

101 genetic diversity of patches in the network to ungrazed controls, but also allows a comparison

102 across patches with varying degrees of connectivity within the network to control for possible

103 direct effects of grazing on growth and reproduction. 


\section{Methods}

\section{Data Collection}

106 This study was conducted in the Franconian Alb, Germany in a $10 \mathrm{~km} \mathrm{x} 15 \mathrm{~km}$ study area,

107 containing 96 calcareous grassland fragments embedded in a matrix of agriculture, forest, and

108 settlements. Abandonment of traditional grazing practices over the past century has led to a

109 significant loss of grasslands, and previously contiguous patches have been fragmented by forest

110 succession and urban development (Dolek and Geyer 2002). In 1989, an ecological connectivity

111 network was implemented to reconnect fragmented grassland via rotational shepherding. The

112 network consists of three non-overlapping shepherding routes (Fig. 1). Prior to the

113 implementation of the network, a baseline survey was conducted to record all vascular plants in

114 previously abandoned grassland patches (Boehmer et al. 1990) and in 2009 this survey was

115 repeated (Wagner et al. 2013).

116 The early-flowering perennial herb Pulsatilla vulgaris (Ranunculaceae) is a flagship

117 species of calcareous grasslands across central Europe and of considerable conservation concern,

118 designated as "near threatened" (IUCN 2015). It is hermaphroditic and mainly outcrossing, and

119 typically produces between one and three purple flowers in early spring (March-April) that each

120 yield 40-100 seeds (Wells and Barling 1971). Seeds have long, feathery styles, and although they

121 appear to be adapted for wind dispersal, those carried by wind rarely disperse further than $20 \mathrm{~cm}$

122 from the plant (Wells and Barling 1971). Although it is possible that deer and small mammals

123 occasionally transport seeds of $P$. vulgaris, these effects are likely small compared to the

124 potential movement of seeds by the large flocks of sheep (400-800 ewes per herd) that move

125 among grassland patches within the ecological connectivity network. The main pollinators of $P$.

126 vulgaris are the small-bodied bees Andrena bicolor, Lasioglossum lineare, and Osmia bicolor 
127 (Fay and Barlow 2014; Kratochwil 1988). They have limited foraging ranges (180-600 m

128 maximum foraging range for similar size bees; Gathmann and Tscharntke 2002; Zurbuchen et al.

129 2010) and thus likely do not contribute strongly to between-population gene flow.

130 From April to May 2009, we collected leaf material of flowering individuals $(n=1,449)$

131 from all patches $(n=57)$ containing $P$. vulgaris. Seven patches have been colonized by $P$.

132 vulgaris since the survey conducted in 1989 (see Table A.1 for details), and analyses of patch

133 occupancy and colonization rates can be found elsewhere (Rico et al. 2012; Wagner et al. 2013).

134 All flowering individuals were sampled in populations with fewer than 40 individuals. For

135 populations that exceeded 40 individuals, we collected leaves from 30-40 flowering plants from

136 across the population. We made note of eight populations that had large numbers of non-

137 flowering individuals. Three of these were consistently grazed, four were intermittently grazed,

138 and only one was ungrazed. With the exception of two large, intermittently grazed populations,

139 we collected a mix of flowering and non-flowering individuals from these populations. Of the 57

140 patches containing $P$. vulgaris, 19 are 'core areas' that have been consistently grazed over the

141 last $200+$ years. The remaining 38 are 'previously abandoned' patches that had been abandoned

142 since at least 1960, and since the implementation of the management program have been either

143 consistently grazed (every year, 3-5 times/season, $n=15$ ), intermittently grazed (grazed only

144 within the first few years after 1989, $n=7$ ), or have remained ungrazed or grazed only late in the

145 growing season $(n=16)$. Note that we found no differences in allelic richness between core areas

146 and previously abandoned patches and so do not distinguish between them in further analyses.

147 Unlike Rico et al. (2012), we lumped patches that are grazed only late in the season (August and

148 onwards, once per year) together with ungrazed patches, since $P$. vulgaris is an early-flowering

149 species and we expect seed dispersal to occur shortly after seeds ripen in May (Wells and Barling 
150 1971). This did not have an effect on our results (see Results). Populations with fewer than five

151 individuals were excluded to prevent bias of population-level measures of genetic diversity and

152 differentiation, giving a final sample size of 49 populations (31 consistently grazed, 6

153 intermittently grazed, 12 ungrazed). In the field, population size was estimated from the number

154 of flowering and non-flowering individuals and categorized as <40 individuals, 40-100

155 individuals, or $>100$ individuals, following the scheme of Rico et al. (2014a). Census population

156 size (i.e. actual counts of individuals) was recorded only for patches with fewer than 40

157 individuals and in patches where we collected fitness data (see below). Note that because plants

158 can reproduce clonally by forming satellite rosettes, individuals within $30 \mathrm{~cm}$ of each other were

159 counted as a single individual.

160 We extracted genomic DNA from dried leaves using QIAGEN DNeasy Plant Mini Kit

161 (QIAGEN, Mississauga, ON, Canada) following the manufacturer's protocol. P. vulgaris is

162 allotetraploid $(2 n=4 x=32$; Wells and Barling 1971), and to simplify analysis we used

163 microsatellite markers developed for this species that could be analyzed as diploid (DiLeo et al.

164 2015; Wolfe 2001). For each individual, we amplified seven species-specific microsatellites in

165 two multiplex reactions (Multiplex A: PV2, PV27, PV65a PV65b; Multiplex B: PV7, PV33,

166 PV56), conducted fragment analysis and genotyping, following the protocols described in DiLeo

167 et al. (2015). Microsatellite loci were tested for departures from Hardy-Weinberg Equilibrium

168 (HWE) and linkage equilibrium using exact tests in GENEPOP 4.2 (Raymond and Rousset

169 1995).

170 In June 2013 we collected mature seed heads to measure fitness-related traits from 7-10

171 individuals in 10 populations (Fig. 1). We chose a combination of populations that differed in

172 size, isolation, and grazing intensity, with wide coverage across the study region. To control for 
173 variation in seed production due to flowering phenology, flower buds were marked in

174 populations within the same two-day time period during peak flowering in April, and seeds were

175 collected from the marked flowers once matured. In the laboratory, developed and undeveloped

176 seeds were counted, and the developed seeds were weighed per seed head with feathery styles

177 removed. Developed seeds were easy to visually distinguish from undeveloped seeds based on

178 size of both the seed and style (Fig. A.1). Fitness traits were measured from only a single seed

179 head per individual plant.

180

181 Genetic Analysis of Functional Connectivity

182 We tested three hypotheses of functional connectivity in P. vulgaris:

183 (1) Isolation by distance (IBD). This is a simple hypothesis of diffusion, where populations

184 that are geographically close will exchange more migrants, and thus experience more

185 gene flow, than populations that are more distant.

186 (2) Least cost distance (LCP). This hypothesis posits that the intervening landscape matrix

187 shapes gene flow among populations. We specifically test the hypothesis that semi-

188 natural open habitat between populations facilitates movement of pollinators and thus

189 gene flow.

190 (3) Isolation by shepherding distance (IBS). This hypothesis assumes that sheep are acting as

191 seed dispersal vectors, and thus populations that are closer together in the topology of the

192 shepherding network will exchange more gene flow.

193 For each of these hypotheses, we calculated an index of connectivity for each population

194 using Hanski's $S_{i}$ index (Hanski 1994). The $S_{i}$ index calculates population connectivity by

195 summing distances between focal population $i$ and all source populations $j$ using the equation: 
$196 S_{i}=\sum_{i \neq j} \exp \left(-\alpha d_{i j}\right)$

197 where $d_{i j}$ is the distance between population $i$ and population $j$, and $\alpha$ is a constant scaling

198 parameter accounting for dispersal capacity, which we fitted through optimization (see below).

199 For $S i_{i B D}, d_{i j}$ was calculated as the Euclidean geographic distance between patches, and for SiLCP,

$200 d_{i j}$ was calculated as the least cost path through open habitat between patches. Open habitat was

201 delimited from digital land use maps, resampled to a resolution of $25 \mathrm{~m}$ (Tatsaechliche Nutzung,

202 ALKIS 2008-2009; Bayerische Vermessungsverwaltung, Munich, Germany; Fig. A.2), and

203 included permanent grasslands, groves, mires, barren land, orchards, and small roads/tracks,

204 which are known to be suitable habitat for wild bees (Steffan-Dewenter et al. 2002). Least cost

205 paths were calculated using the gdistance library (van Etten 2012) in $R$. For $S i_{I B S}, d_{i j}$ was

206 calculated as the number of patches traversed by sheep to get from $j$ to focal patch $i$, and pairs of

207 patches from different grazing routes or that were intermittently grazed or ungrazed were given a

$208 d_{i j}$ value of 100 assuming that gene flow outside of the grazing routes is rare (Rico et al. 2012).

209 Intermittently grazed populations and those grazed only late in the season were not included as

210 steps in the network because they likely do not contribute as strongly to functional connectivity

211 compared to consistently grazed populations, which have been in the network since 1989 and are

212 grazed up to five times per year. However, for comparison, we also calculated shepherding

213 connectivity including intermittently grazed and late grazed populations as steps in the network.

214 Grassland patches in the network that did not contain P. vulgaris populations (Fig. 1) were

215 counted as steps traversed by sheep in the calculation of $\operatorname{Si}_{I B S}$.

216 The parameter $\alpha$ should be set to a value that is equal to $1 /$ mean dispersal distance. Since

217 we do not know the mean dispersal of $P$. vulgaris, we optimized $\alpha$ for each connectivity

218 hypothesis separately by testing a range of values and choosing the value that gave the highest $\mathrm{R}^{2}$ 
219 in univariate regression with allelic richness $\left(A_{r}\right)$. Sheep have the ability to transport seeds of

220 grassland plants up to several hundred kilometers, and can retain seeds in their wool for several

221 months (Fischer et al. 1996), thus for SiIBS we explored a wide range of $\alpha$ values from 0.08-1

222 which translates to mean dispersal distances between 1-13 steps (the maximum in our network)

223 through the grazing network. In contrast, gene flow via pollinators or wind-dispersed seeds

224 should occur at much smaller spatial scales for P. vulgaris, and so for both $S_{I B D}$ and $S i_{L C P}$ we

225 explored $\alpha$ values between $0.2-2$ which translates to mean dispersal distances between $0.5-5 \mathrm{~km}$.

226 Based on this optimization procedure, we set $\alpha=0.2$ (mean dispersal of $5 \mathrm{~km}$ ) for both $\operatorname{Si}_{I B D}$ and

$227 S_{L C P}$ and $\alpha=0.08$ (mean dispersal of $\sim 12$ steps through the network) for SilBS. Note that that our

228 goal was not to determine true $\alpha$, but to compare the predictive power of each of the three

229 hypotheses of functional connectivity.

230 We tested the strength of evidence for each of these hypotheses of functional connectivity

231 by testing their associations with genetic differentiation using the program GESTE 2.0 (Foll

232 and Gaggiotti 2006). This program calculates population-specific $\mathrm{F}_{\text {st }}$ values, which represent

233 how differentiated each population is from others in the sample. GESTE uses a Bayesian

234 approach that includes non-genetic information as a prior, and models associations between these

235 non-genetic predictors and population-specific $\mathrm{F}_{\mathrm{st}}$ with generalized linear models. This approach

236 has low Type I error rates compared to the commonly used Mantel test, and has performed well

237 in recovering landscape and ecological drivers of gene flow in simulations (Balkenhol et al.

238 2009; Foll and Gaggiotti 2006). We first ran GESTE on all populations ( $n=49)$, including four

239 predictors: $S i_{I B D}$, SiLCP, population size class $(<40,40-100,>100$ individuals included as an

240 ordinal variable: 1,2,3), and grazing intensity (ungrazed, intermittently grazed, or consistently

241 grazed, included as ordinal: 1,2,3). Note that SiIBS could not be included since connectivity of all 
242 ungrazed populations would be zero. To explicitly test the effects of shepherding on functional

243 connectivity, we ran GESTE separately for consistently grazed populations ( $n=31)$, including the

244 three measures of connectivity ( $\left.S i_{I B D}, S i_{L C P}, S i_{I B S}\right)$, population size class, and grazing route (route

2451,2 , or 3) as predictors. We ran GESTE for a total of 250,000 iterations with 50,000 iterations of

246 burn in.

248 Genetic Diversity

249 We evaluated the effects of grazing treatment (ungrazed, intermittently grazed, consistently

250 grazed), population size class $(<40,40-100,>100$ individuals) and their interaction, on genetic

251 diversity and the inbreeding coefficient $\left(F_{i s}\right)$ with a two-way ANOVA followed by Tukey HSD.

$252 \quad F_{\text {is }}$ was calculated using GENEPOP 4.2 (Raymond and Rousset 1995).

253 Genetic diversity was measured as the mean number of alleles per population $\left(A_{r}\right)$ using

254 the gstudio package (Dyer 2014) in R 3.02 (R Core Team 2016). We used rarefaction with a

255 sample size of five and 999 permutations to control for differences in sample size between

256 populations. Allelic richness was chosen over heterozygosity because it is more sensitive to

257 recent demographic change (Allendorf 1986) and is a better indicator of long-term adaptive

258 potential of populations, even when based on neutral markers (Caballero and Garcia-Dorado

259 2013; Vilas et al. 2015). However, for comparison, we also present results of analyses using two

260 alternative measures of genetic diversity: expected heterozygosity ( $H_{e}$; correlation with $A_{r}$ :

261 Pearson $r=0.93)$, and observed heterozygosity $\left(H_{o}\right.$; correlation with $A_{r}$ : Pearson $\left.r=0.50\right)$.

262 Limiting analyses to consistently grazed patches, we tested the hypothesis that

263 populations that are well-connected within the grazing network (i.e. populations that are

264 separated by shorter shepherding distances from others) have higher genetic diversity than more 
265 isolated populations using linear mixed effect models. We constructed a set of linear mixed

266 effect models to quantify the relationship between genetic diversity $\left(A_{r}\right)$ and four predictors as

267 fixed effects: SiIBD, SiLCP, SiIBS, and population size class, and grazing route (route 1, 2, or 3) as a

268 random effect. We found no significant interactions between connectivity indices and population

269 size class and so we included the latter only as a main effect. We tested sub-models of $A_{r} \sim S i_{I B D}$

$270+S i_{L C P}+S i_{I B S}+$ population size class and used $\mathrm{AIC}_{\mathrm{c}}$ for model selection, however $S i_{I B D}$ and

271 SiLCP were highly correlated (Pearson $r=0.85$ ), therefore we never included them in the same

272 sub-model. We assessed the relative importance of each predictor by summing the Akaike

273 weights of all models that included that predictor. We used likelihood ratio tests to test the

274 significance of individual fixed effects in the top selected models, and report parameter estimates

275 averaged over models with $\Delta \mathrm{AIC}_{\mathrm{c}}<2$. We used the protocol of Nakagawa \& Schielzeth (2013)

276 to calculate marginal $\mathrm{R}^{2}$, which represents variance explained by the fixed effects. We also ran

277 the model on a subset of consistently grazed populations where information on census population 278 size was available $(n=15)$, this time treating population size as a continuous predictor variable.

280 Fitness

281 We evaluated the relationship between genetic diversity $\left(A_{r}\right)$ and two fitness-related traits (seed 282 set, seed mass) in linear mixed effect models in the 10 populations where we collected seeds.

283 Seed set was measured as the proportion of developed seeds per seed head, and seed mass was

284 measured as the mean mass of developed seeds per seed head. The proportion of seed set and the 285 total number of filled seeds per seed head were highly correlated (Pearson $r=0.71$ ). $A_{r}$ was 286 included as a fixed effect and was exponentially transformed to linearize the relationship with 287 seed set and seed mass. Note that fitness-related traits were measured at the level of individuals 
288 within populations, and genetic diversity was measured per population. Population was included

289 as a random effect to control for the non-independence of seed data collected from multiple

290 mother plants within the same patch. Models were estimated in $R$ using lme4 (Bates et al. 2015)

291 using maximum likelihood. We used likelihood ratio tests to determine the significance of the

292 fixed effect, and report marginal $\mathrm{R}^{2}$ (variance explained by fixed effects, Nakagawa and

293 Schielzeth 2013). Data on the number of flowering stems and height of the flowering stem of the

294 plants where we collected seeds were available for seven populations. We tested if these were

295 important predictors of seed set and seed mass in addition to allelic richness in mixed models.

296 Fitness-related traits can be influenced not only by genetic diversity, but also by

297 population size, either directly (e.g. ecological Allee effects; Lande 1988; Reed 2005), or

298 indirectly by increasing genetic diversity (Leimu et al. 2006; Luque et al. 2016). We used

299 Pearson's partial correlations to tease apart the effects of genetic diversity and population size on

300 seed set in $P$. vulgaris populations. Note that for this analysis, seed set was included as a mean

301 value per population. Ideally, a full path analysis would be conducted to quantify the interactions

302 between these variables, but our low sample size ( $n=10$ populations) precluded such a test. We

303 calculated Pearson's product moment correlations between mean seed set per population and $A_{r}$,

304 mean seed set and population size, and partial correlations between mean seed set and $A_{r}$

305 controlling for population size, and mean seed set and population size controlling for $A_{r}$ using the

306 ppcor 1.0 (Kim 2012) in R. Population size was defined as the number of flowering individuals

307 per population. Ar was exponentially transformed and we took the logarithm of population size to 308 linearize relationships. 


\section{Results}

310 Genetic Markers

311 Markers PV7, PV27, PV65a and PV56 showed departures from HWE expectations, but there

312 was no consistent pattern across populations (Table B.1) and all markers were retained. Marker

313 pairs were found to be unlinked (Table B.2).

315 Functional Connectivity

316 Connectivity indices $S i_{I B D}$ and $S i_{L C P}$ were highly correlated, but neither of these were

317 correlated with shepherding connectivity, SilBS (Table A.2). Analysis of genetic differentiation

318 across all 49 populations suggested that $S i_{L C P}$ was a better predictor of overall structure than

$319 S i_{I B D}$, with the highest probability model including $S i_{L C P}$ and grazing intensity as predictors

320 (Pr=0.85; Table 1, Fig. 2). When the analysis was restricted to consistently grazed populations

321 ( $n=31)$, population-specific $\mathrm{F}_{\text {st }}$ was best explained by a model including shepherding

322 connectivity $\left(S i_{I B S}\right)$, with $\mathrm{F}_{\text {st }}$ showing a negative relationship with SiIBS (Table 1 and 2, Fig. 3).

323 This model had a high posterior probability $(\operatorname{Pr}=0.79)$, and in comparison, the next-best model

324 had a very low probability $(\operatorname{Pr}=0.045)$, suggesting that $\mathrm{Si}_{I B S}$ alone fits the data well compared to

325 the other predictors for consistently grazed populations (Table 1). When SiIBS was calculated

326 including intermittently grazed and late grazed populations as steps through the shepherding

327 network, GESTE failed to find an optimal model, with no model having a probability greater than

3280.2 (Table A.3).

329

330 Effects of Shepherding Connectivity on Genetic Diversity 
331 In a two-way ANOVA, both grazing treatment and population size class, but not their

332 interaction, had a significant effect on genetic diversity, $A_{r}$ (ANOVA, grazing treatment:

$333 F_{(2,42)}=7.97, p=0.001$, population size class: $F_{(2,42)}=3.64, p=0.03$, interaction: $F_{(2,42)}=0.55$,

$334 p=0.58)$. However, a posthoc Tukey test showed significant differences among grazing

335 treatments where ungrazed populations had significantly lower genetic diversity than

336 intermittently and consistently grazed populations, but no significant differences among

337 population size classes (Fig. 4). We found significant differences in expected heterozygosity $H_{e}$

338 among grazing treatments but not population size class in a two-way ANOVA (grazing

339 treatment: $F_{(2,42)}=6.56, p=0.003$, population size class: $F_{(2,42)}=2.66, p=0.08$, interaction:

$\left.340 F_{(2,42)}=0.23, p=0.79\right)$, and found no significant differences in observed heterozygosity $H_{o}$

341 (ANOVA, grazing treatment: $F_{(2,42)}=1.38, p=0.26$, population size class: $F_{(2,42)}=0.44, p=0.65$,

342 interaction: $F_{(2,42)}=1.26, p=0.29$ ) nor inbreeding coefficient $F_{i s}$ (ANOVA, grazing treatment:

$343 F_{(2,42)}=0.1, p=0.91$, population size class: $F_{(2,42)}=0.23, p=0.79$, interaction: $\left.: F_{(2,42)}=1.04, p=0.36\right)$.

344 When late grazed populations were removed from the ungrazed category, we still found

345 significant differences in $A_{r}$ between ungrazed and consistently grazed populations (ANOVA,

346 grazing treatment: $F_{(1,34)}=5.53, p=0.02$, population size class: $F_{(2,34)}=2.98, p=0.06$, interaction:

$\left.347 \quad F_{(1,34)}=1.09, p=0.3\right)$.

348 Genetic diversity $\left(A_{r}\right)$ of consistently grazed populations was best fit by a linear mixed

349 effect model including connectivity by shepherding ( $\left.\mathrm{Si}_{I B S}\right)$ and population size class as fixed

350 factors (Table 3, Fig. 3). This model explained significant variation beyond the grazing-route

351 random effect (likelihood ratio test, $\chi^{2}(1)=18.4, p<0.0001$ ), and tests for the significance of

352 individual fixed factors showed that both $S i_{I B S}$ (likelihood ratio test, $\left.\chi^{2}(1)=7.6, p=0.006\right)$ and

353 population size class (likelihood ratio test, $\chi^{2}(1)=4.9, p=0.03$ ) had a significant positive effect on 
$354 A_{r}$ (Table 3, Table 4, Fig. 3). In comparison, neither $S_{L C P}\left(\right.$ likelihood ratio test, $\left.\chi^{2}(1)=2.1, p=0.14\right)$

355 nor $\operatorname{Si}_{I B D}$ (likelihood ratio test, $\chi^{2}(1)=1.3, p=0.24$ ) had significant effects in the top models in

356 which they appeared (Table 3), and estimated effects on $A_{r}$ were negative ( $A_{r}$ decreased with

$357 S i_{I B D}$ and $S i_{L C P}$; Table 4). The same model was chosen when we ran the model treating

358 population size as a continuous variable for the fifteen populations where census population size

359 was available (Table A.4, Fig. A.3), and when $H_{e}$ was used as the response variable (Table A.5).

360 When $H_{o}$ was used as the response variable, the top model included only the shepherding-route

361 random effects, and in general all models explained little variation as assessed by marginal $R^{2}$

362 (Table A.5).

363

364 Effect of Genetic Diversity on Fitness

365 Seed set and allelic richness $\left(A_{r}\right)$ showed a significant positive linear association (Likelihood

366 ratio test: $\chi^{2}(1)=9.2, p=0.002$; marginal $R^{2}=0.12$; Fig. 5a), and the same positive relationship was

367 found when seed set was measured as the total number of seeds per seed head, although the

368 strength of association was weaker (Fig. A.4). Seed mass also showed a significant positive

369 association with $A_{r}$ (Likelihood ratio test: $\chi^{2}(1)=11.76 p<0.0001$; marginal $R^{2}=0.23$; Fig. 5b).

$370 \quad$ Seed set and seed mass showed a significant positive linear association with expected

371 heterozygosity $\left(H_{e}\right)$ but not observed heterozygosity $\left(H_{o}\right.$; Table A.6). In the seven populations

372 where data were available, we found that the height of the flowering stem had a significant

373 positive relationship with the total seed set in addition to significant effects of $A r$ (Table A.7, Fig.

374 A.5).

375 Mean seed set per population showed strong positive correlations with both $A_{r}(r=0.82$,

$376 p=0.003)$, and population size $(r=0.71, p=0.02)$. The partial correlation between mean seed set 
377 and $A_{r}$ remained significant after controlling for population size ( $r=0.64, p=0.03$ ), whereas the 378 partial correlation between mean seed set and population size controlling for $A_{r}$ was not 379 significant $(r=0.32, p=0.37)$. 


\section{Discussion}

381 Here we demonstrate the utility of an ecological connectivity network to maintain functional

382 connectivity and genetic diversity of populations of an imperiled wildflower, Pulsatilla vulgaris,

383 in calcareous grasslands in Germany. Genetic data of grazed populations were best fit by a model

384 of connectivity that incorporated the number of patches traversed by sheep in the shepherding

385 network, suggesting that connectivity by shepherding, and not the geographic distance separating

386 grassland patches or least-cost path distance through open habitat determines functional

387 connectivity. We further show that enhanced connectivity within the shepherding network

388 translated to enhanced genetic diversity, and that populations with higher genetic diversity

389 produced more and heavier seeds. Together these results suggest that shepherding is an effective

390 management measure to sustain functional connectivity among fragmented populations of $P$.

391 vulgaris, but populations that are small and unconnected, or small with low connectivity in the

392 shepherding network still suffer from reduced genetic diversity.

\section{Functional Connectivity}

395 Our results suggest that geographic distance is a poor predictor of genetic connectivity of $P$.

396 vulgaris populations. In contrast, connectivity through open habitat $\left(S i_{L C P}\right)$, and shepherding

397 connectivity $\left(S i_{I B S}\right)$ showed strong negative associations with population-specific Fst $($ Fig. 2, Fig.

398 3). When all populations were analysed together, $S i_{L C P}$ and grazing intensity explained patterns

399 of genetic differentiation better than either $\operatorname{Si}_{I B D}$ or population size class. However, shepherding

400 connectivity was the single best predictor of genetic differentiation of consistently grazed

401 populations (Table 1). This suggests that shepherding contributes strongly to genetic connectivity

402 of consistently grazed populations, but that the movement of pollinators through open habitat 
403 might be additionally important, particularly for populations outside of the shepherding network.

404 This highlights the importance of considering the potential vectors of pollen and seed dispersal

405 and their effect on functional connectivity when designing ecological connectivity networks, and

406 shows that considering patch proximity alone may not be enough to ensure dispersal and

407 subsequent gene flow between fragmented populations (Auffret et al. 2017; DiLeo et al. 2014;

408 Dyer et al. 2012; Kamm et al. 2010).

Previous work in this system showed that the rotational shepherding network predicted

411 demographic connectivity for P. vulgaris and other typical grassland species at the community

412 (Rico et al. 2012) and species level (Rico et al. 2014a), and at the genetic level for another

413 grassland plant, Dianthus carthusianorum (Rico et al. 2014b). The current study suggests that the

414 same trend holds true at the genetic level for $P$. vulgaris, where both genetic differentiation and

415 genetic diversity were best fit by a model including connectivity via shepherding (Tables 1 and

416 3). The effects of fragmentation can manifest at different spatial and temporal scales depending

417 on the population outcome measured (e.g. patch occupancy or abundance versus genetic

418 diversity; Jackson and Fahrig 2014; Takkis et al. 2013) and the importance of considering both

419 demographic and genetic factors for conservation planning is increasingly recognized (Landguth

420 et al. 2014; Luque et al. 2012). Demographic outcomes such as patch occupancy and abundance

421 are mediated by the processes of recruitment and colonization, which in plants occurs through

422 the dispersal of seed. Note that in P. vulgaris and other calcareous grassland plants, colonization

423 and establishment success depends on pre- and post-dispersal effects such as microsite

424 conditions (Piqueray et al. 2013), and this may explain why some patches remain unoccupied in

425 our study region (Rico et al. 2012; Wagner et al. 2013). In contrast, genetic differentiation and 
426 genetic diversity of local populations is the product of gene flow over generations, and is thought

427 to mainly occur through pollination for most plant species (Ellstrand 1992; Ennos 1994).

428 However, in some systems the contribution of seed to overall genetic connectivity far exceeds

429 that of pollen, particularly when seeds are dispersed by animal vectors (Bacles et al. 2006;

430 Manzano and Malo 2006). This may explain why we find such a strong effect of shepherding

431 connectivity. The ecological network investigated in this study is different from many others as it

432 directly provides the functional vectors of seed dispersal (i.e. sheep) rather than protecting

433 physical aspects of the landscape that have the potential to support connectivity by either seed or

434 pollen. In comparison, our results suggest that pollen-mediated gene flow contributes less to

435 overall genetic connectivity; despite being highly connected by suitable pollinator habitat,

436 ungrazed populations had much higher genetic differentiation than grazed populations (Fig. 2).

437 These results are further supported by previous work conducted on a subset $(n=7)$ of the $P$.

438 vulgaris populations included here, which showed that most pollination occurred within ten

439 meters of the mother plant, and only $16 \%$ of all pollination events could be attributed to among-

440 population pollen flow (DiLeo 2016).

441

442 Effect of Shepherding Connectivity on Genetic Diversity

443 We found that intermittently and consistently grazed populations had significantly higher allelic

444 richness than ungrazed populations (Fig. 4). This suggests that the populations of P. vulgaris that

445 are incorporated into the ecological connectivity network harbor more genetic variation and thus

446 may be better able to endure future environmental change. However, it is unclear if the observed

447 effect is due to the enhanced connectivity provided by the ecological network or a direct result of

448 the grazing process. For example, grazing can influence plant reproductive success by altering 
449 vegetation height and habitat quality (de Vere et al. 2009; Jacquemyn et al. 2003), flowering

450 phenology (Lennartsson et al. 2012) or richness and abundance of pollinators (Kormann et al.

$4512015)$. When we restricted analyses to only those populations within the ecological connectivity

452 network to control for direct reproductive effects of grazing (i.e. ecological Allee effects; Lande

453 1988; Luque et al. 2016), we found that genetic diversity significantly increased with both

454 shepherding connectivity and populations size (Si $I_{I B S}$; Table 4; Fig. 3). This suggests that the

455 functional connectivity provided by the ecological network maintains genetic diversity of

456 populations, but importantly, populations that are small and have low connectivity within the

457 network still experience low levels of allelic richness. These small, isolated populations may be

458 useful targets for connectivity network optimization and restoration (Mijangos et al. 2015). It is

459 also apparent from Fig. 3 that there are differences in the levels of diversity among the three

460 grazing routes, suggesting that they may have different levels of standing variation. Unsampled

461 P. vulgaris populations exists to the south of our study region, and it is possible that these

462 population exchange gene flow with populations in route 3 , possibly explaining this routes

463 increased levels of genetic variation. The differences in shepherding route-level connectivity

464 likely also contributes-to and compounds this effect; for example, populations in route 1 tend to

465 suffer from the lowest connectivity and also have the lowest genetic diversity.

467 Effect of Genetic Diversity on Fitness

468 We found that higher genetic diversity translated to an increase in both mean seed set and seed

469 mass of populations (Fig. 5). Strong positive correlations between genetic diversity and fitness

470 have been observed in a number of plant species (reviewed in Leimu et al. 2006; Reed and

471 Frankham 2003), and populations with higher fitness have a higher probability of persistence 
472 (Frankham 2005). However, our results should be interpreted with caution given our low sample

473 size ( $n=10$ populations) and that we measured fitness-related traits in a single year for a long-

474 lived species. Given these caveats, it is surprising to see such a strong effect of genetic diversity

475 on seed set, with $64 \%$ of variation explained after controlling for population size. Further work is

476 required to determine how the magnitude of differences in seed set and seed mass between

477 populations of low and high diversity translates to germination success and seedling survival in 478 the field.

The lack of variation in $\mathrm{F}_{\mathrm{is}}$ and observed heterozygosity $\left(\mathrm{H}_{\mathrm{o}}\right)$ across populations was

481 surprising given that we found a strong correlation between shepherding connectivity and allelic

482 richness $\left(A_{r}\right)$, and $A_{r}$ and both measured fitness-related traits. Allelic richness degrades in

483 populations (or in this case, increases in populations) faster than heterozygosity (Maruyama and

484 Fuerst 1985), which suggests that the effects of shepherding connectivity are recent. This lack of 485 variation in $F_{i s}$ and $H_{o}$ also suggests that inbreeding is not the reason for the low reproductive 486 success in populations with low diversity. One explanation for this result is that the increase in 487 fitness does not have a genetic basis but is rather the result of an ecological Allee effect, where 488 density-dependent mating success or facilitation in large populations leads to higher seed 489 production (Lande 1988). This has been demonstrated in a number of plant systems (reviewed in 490 Reed 2005), including P. vulgaris where Hensen et al. (2005) found strong positive correlations 491 between population size and both seed set and seed mass in central Germany. However, we 492 found that after controlling for the effects of genetic diversity, the partial correlation between 493 seed set and population size was no longer significant. This suggests that population size does 494 not directly influence fitness, but that large populations have higher genetic diversity, which in 
495 turn have higher seed set (i.e. a genetic Allee effect; Luque et al. 2016). An alternative

496 explanation is that pollination plays an important role in maintaining both genetic diversity and

497 fitness of $P$. vulgaris populations. For example, Breed et al. (2012) found that the diversity of

498 pollen received by flowers was more important than inbreeding in determining progeny fitness in

499 Eucalyptus socialis. Sampling more diverse pollen sources opens up the opportunity for female

500 selection of more compatible pollen grains or 'good genes', resulting in increased fitness that is

501 independent of inbreeding (Armbruster and Rogers 2004; Yasui 1998). Populations with higher

502 diversity will act as more diverse pollen sources, and likewise populations with higher

503 connectivity will receive more immigrants which introduce new variation into populations by

504 providing outside pollen.

505

506

507 Conclusions

508 Here we show that an ecological connectivity network in southern Germany has been successful

509 at maintaining functional connectivity of a flagship wildflower, and that this enhanced

510 connectivity translated to enhanced genetic diversity of populations. We found a significant

511 relationship between genetic diversity and two fitness-related traits, emphasizing the importance

512 of preserving genetic diversity. Incorporating ungrazed populations into the existing network

513 may be a suitable conservation measure to boost genetic diversity and fitness, and small

514 populations that are more isolated within the network might benefit from further optimization of

515 the network topology. This study empirically demonstrates the pathway of predicted positive

516 associations between connectivity, genetic diversity, and fitness in the context of an ecological

517 network, and provides a framework for testing the efficacy of ecological networks for focal 
518 species using genetic tools. Taken together with previous work in this system which showed that

519 shepherding maintains species richness (Wagner et al. 2013) and demographic connectivity

520 (Rico et al. 2012, 2014a) at the community level, these results suggest a positive role of

521 ecological shepherding networks for protecting two of the three levels of biodiversity

522 recommended for conservation by the International Union for Conservation of Nature (McNeely

523 et al. 1990) - species and genetic diversity (the third level is ecosystem diversity) - for

524 calcareous grassland plants.

525

526 Acknowledgements

527 Funding was provided by the Natural Sciences and Engineering Research Council of Canada 528 (NSERC CGS-D, CREATE-ADVENT and Michael Smith Foreign Study Supplement to M.F.D, 529 and Discovery Grant to H.H.W.) and the Government of Central Franconia, Bavaria, Germany.

530 We thank M-J. Fortin, M.T.J Johnson, R. Ness, and N. Keygohbadi for comments on an earlier

531 version of this manuscript, and R. Holderegger for helpful discussions. We thank Paul Beier and

532 two anonymous reviewers for comments that greatly improved this manuscript. We thank K.

533 Dadrich, D. Baumgartner, B. Raab, S. Haacke, and H. Lehnert for support in the field, A.

534 Lochab, and M. Liu for help in the lab, and the shepherds E. Beil, E. Neulinger, A. Grimm for 535 detailed information on management strategies and their implementation. 
536 Table 1. The top five posterior probability models describing the effects of connectivity

537 (geographic connectivity, SiIBD; least cost connectivity through open habitat, SiLCP; shepherding

538 connectivity, $S i_{I B S}$ ) and population size class (pop.size) on population-specific $\mathrm{F}_{\text {st }}$ when all

539 populations were analysed together (top) and when data were subset to consistently grazed

540 populations (lower). Note that shepherding distance was not included as a predictor in the

541 analysis of all populations (see Methods for details). Regression coefficients for the top

542 supported models (bolded) are presented in Table 2.

543

\begin{tabular}{|c|c|c|}
\hline Population subset & Model & Probability \\
\hline \multirow{5}{*}{$\begin{array}{l}\text { All populations } \\
\qquad(n=49)\end{array}$} & $\mathrm{F}_{\mathrm{st}} \sim$ grazing.intensity $+S i_{L C P}$ & 0.85 \\
\hline & $\mathrm{F}_{\mathrm{st}} \sim$ grazing.intensity + SiLCP + pop.size & 0.06 \\
\hline & $\mathrm{F}_{\mathrm{st}} \sim$ grazing.intensity $+S i_{L C P}+S i_{I B D}$ & 0.04 \\
\hline & $\mathrm{F}_{\mathrm{st}} \sim$ grazing.intensity + SiIBD & 0.02 \\
\hline & $\mathrm{F}_{\mathrm{st}} \sim S i_{L C P}$ & 0.01 \\
\hline \multirow{5}{*}{$\begin{array}{c}\text { Consistently } \\
\text { grazed populations } \\
(n=31)\end{array}$} & $F_{s t} \sim S i_{I B S}$ & 0.79 \\
\hline & $\mathrm{F}_{\mathrm{st}} \sim S i_{I B S}+$ Route & 0.05 \\
\hline & $\mathrm{F}_{\mathrm{st}} \sim S i_{I B S}+S i_{L C P}$ & 0.04 \\
\hline & $\mathrm{F}_{\mathrm{st}} \sim \operatorname{Si}_{I B S}+\operatorname{Si}_{I B D}$ & 0.04 \\
\hline & $\mathrm{F}_{\mathrm{st}} \sim S i_{I B S}+$ pop.size & 0.03 \\
\hline
\end{tabular}


545 Table 2. Regression coefficients for the top probability model identified by GESTE explaining

546 variation in population-specific $\mathrm{F}_{\text {st }}$ across all populations (top) and consistently grazed

547 populations (bottom). The top model for the analysis conducted on all populations included

548 grazing intensity and least cost connectivity through open habitat $\left(S i_{L C P}\right)$ as predictors. The top

549 model for consistently grazed populations included shepherding connectivity ( $\left.i_{I B S}\right)$ as a

550 predictor. The highest probability density interval (HDPI), which indicates the smallest interval

551 that contains $95 \%$ of values, is shown.

552

\begin{tabular}{llcc}
\hline Population Subset & Variable & Estimate & HDPI $(95 \%)$ \\
\hline All populations & constant & -3.40 & $(-3.58,-3.22)$ \\
$(n=49)$ & grazing intensity & -0.33 & $(-0.522,-0.14)$ \\
& $S i_{L C P}$ & -0.41 & $(-0.611,-0.232)$ \\
\hline Consistently grazed & constant & -3.40 & $(-3.62,-3.18)$ \\
populations $(n=31)$ & $S i_{I B S}$ & -0.45 & $(-0.663,-0.294)$ \\
\hline
\end{tabular}

553 
554 Table 3: Results of model selection and model fit of linear mixed effect models testing the effect 555 of geographic connectivity $\left(S_{I B D}\right)$, least cost path connectivity $\left(S_{L C P}\right)$, shepherding connectivity $556\left(S_{I B S}\right)$, and population size class (pop.size) on genetic diversity $\left(A_{r}\right)$ of $P$. vulgaris populations.

557 All models included grazing route (route 1, route 2, or route 3 ) as a random effect (1|Route).

558 Model weights $\left(w_{i}\right)$ and marginal $\mathrm{R}^{2}$ of fixed effects are shown. Model averaged estimates of 559 parameters for models with $\triangle \mathrm{AICc}<2$ are shown in Table 4.

\begin{tabular}{|c|c|c|c|c|}
\hline Model & $\mathrm{AIC}_{\mathrm{c}}$ & $\Delta \mathrm{AIC}_{\mathrm{c}}$ & $w_{i}$ & $R^{2}$ \\
\hline$A_{r} \sim \operatorname{Si}_{I B S}+$ pop.size $+1 \mid$ Route & 11.1 & 0 & 0.31 & 0.60 \\
\hline$A_{r} \sim S i_{I B S}+S i_{L C P}+$ pop.size $+1 \mid$ Route & 12.0 & 1.0 & 0.19 & 0.63 \\
\hline$A_{r} \sim S i_{I B S}+S i_{I B D}+$ pop.size $+1 \mid$ Route & 12.8 & 1.7 & 0.13 & 0.62 \\
\hline$A_{r} \sim S i_{I B S}+S i_{L C P}+1 \mid$ Route & 13.0 & 1.9 & 0.12 & 0.58 \\
\hline$A_{r} \sim$ SiIBS $+1 \mid$ Route & 13.2 & 2.1 & 0.11 & 0.53 \\
\hline$A_{r} \sim S i_{I B S}+S i_{I B D}+1 \mid$ Route & 13.9 & 2.8 & 0.08 & 0.56 \\
\hline$A_{r} \sim$ pop.size $+1 \mid$ Route & 15.8 & 4.7 & 0.03 & 0.17 \\
\hline$A_{r} \sim$ SilBD + pop.size $+1 \mid$ Route & 16.9 & 5.9 & 0.02 & 0.19 \\
\hline$A_{r} \sim S i_{L C P}+$ pop.size $+1 \mid$ Route & 18.2 & 7.2 & 0.01 & 0.18 \\
\hline$A_{r} \sim 1 \mid$ Route & 24.0 & 12.9 & 0 & NA \\
\hline$A_{r} \sim \operatorname{Si}_{I B D}+1 \mid$ Route & 25.9 & 14.8 & 0 & 0.02 \\
\hline$A_{r} \sim S i_{L C P}+1 \mid$ Route & 26.6 & 15.6 & 0 & 0.001 \\
\hline
\end{tabular}


561 Table 4: Model averaged parameter estimates showing the effect of each variable (geographic

562 connectivity, $S i_{I B D}$; least cost connectivity through open habitat, $S i_{L C P}$; shepherding connectivity,

563 SiIBS; population size class, pop.size) on allelic richness. Averaging was conducted over four

564 models with $\triangle \mathrm{AICc} \leq 2$ after model selection (see Table 3). Adjusted standard errors and

565 confidence intervals of each parameter, and the relative importance of each predictor variable is

566 shown.

\begin{tabular}{lcccc}
\hline Variable & Estimate & $\begin{array}{c}\text { Standard } \\
\text { Error }\end{array}$ & $\begin{array}{c}\text { Confidence } \\
\text { Interval }\end{array}$ & $\begin{array}{c}\text { Relative } \\
\text { Importance }\end{array}$ \\
\hline (Intercept) & 3.04 & 0.38 & $(2.30,3.78)$ & \\
Si $i_{B S}$ & 0.24 & 0.04 & $(0.16,0.33)$ & 1.00 \\
pop.size & 0.10 & 0.05 & $(0.01,0.20)$ & 0.84 \\
Si $i_{L C P}$ & -0.02 & 0.01 & $(-0.04,0.005)$ & 0.41 \\
Si $i_{\text {IBD }}$ & -0.01 & 0.01 & $(-0.04,0.01)$ & 0.17 \\
\hline
\end{tabular}




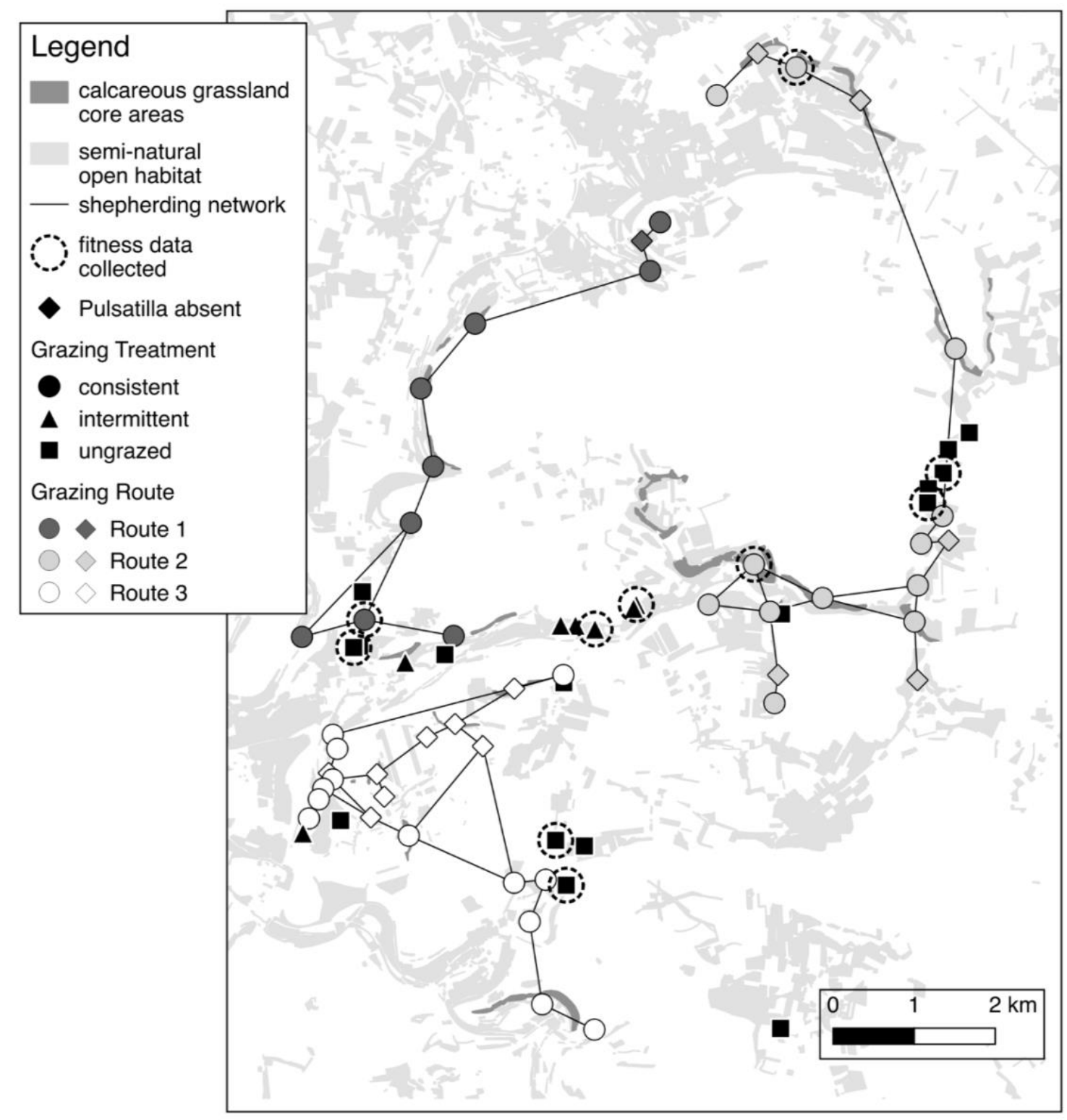

570 Figure 1: Location of calcareous grassland patches and grazing treatment of patches in the study

571 area in the Franconian Alb, Germany. Grazing routes connecting consistently grazed populations

572 are indicated by black lines and labelled with the associated route. Dashed circles indicate

573 populations where fitness-related traits were measured. Semi-natural open habitat is shown in

574 light grey and core calcareous grassland patches ('core areas', see Methods for details) are

575 indicated in dark grey. 

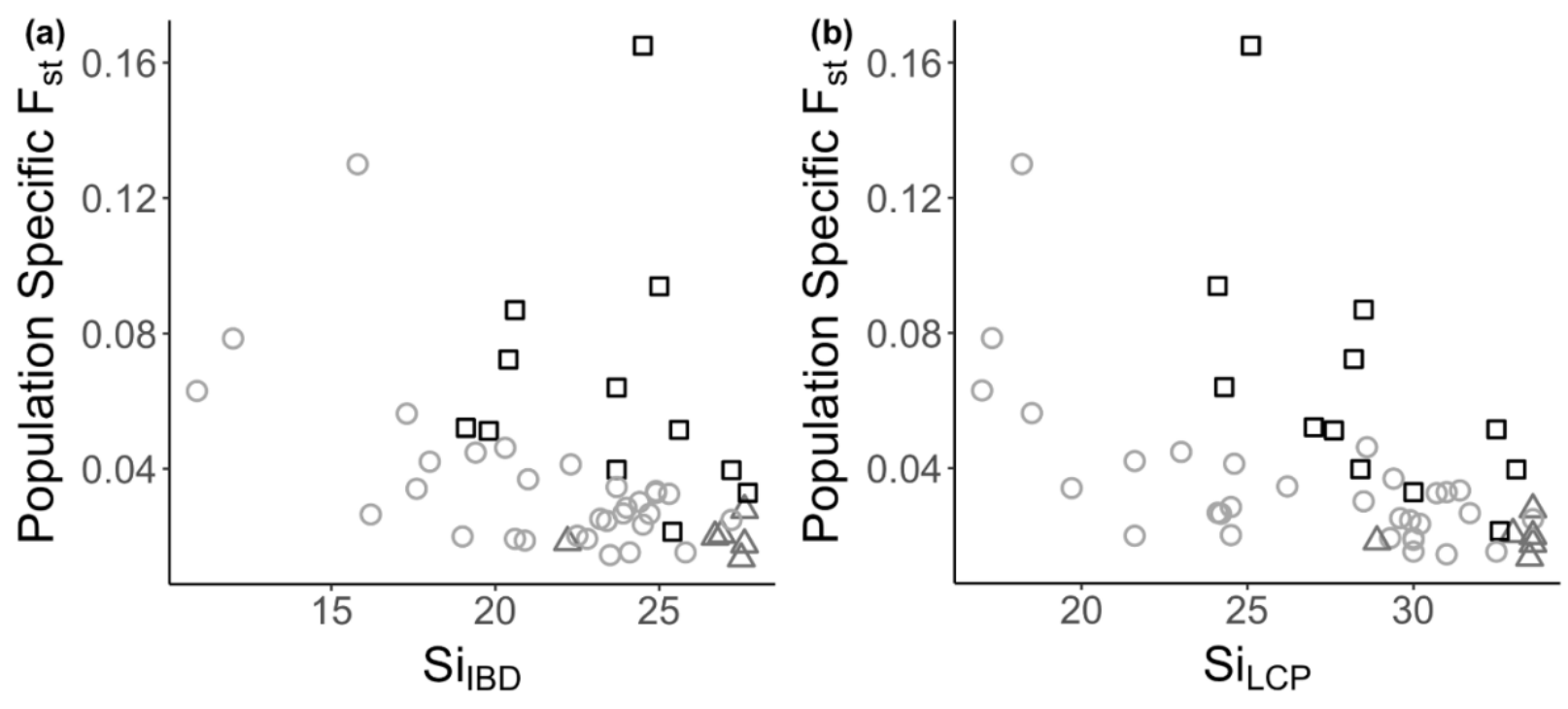

579 Figure 2: Scatterplots showing the relationship between genetic differentiation (population580 specific $\left.\mathrm{F}_{\mathrm{st}}\right)$ and geographic connectivity $\left(S i_{I B D}\right)$, and least-cost path connectivity through open 581 habitat $\left(S i_{L C P}\right)$. Each point represents a single population $(n=49)$ and shape and color indicates 582 grazing treatment (circles, consistently grazed populations; triangles, intermittently grazed 583 populations; squares, ungrazed populations). See Table 1 for results of model selection on these 584 data. 

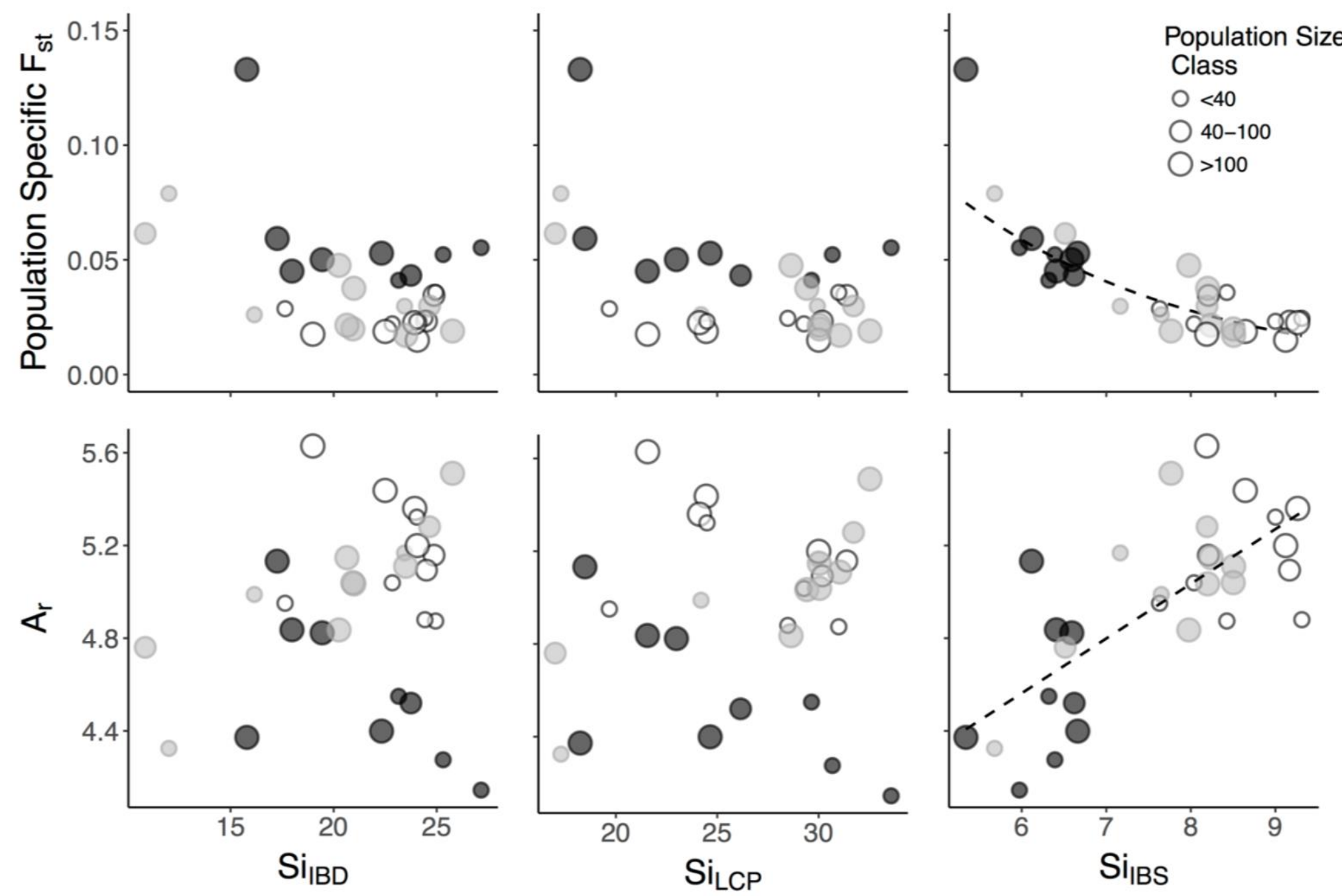
586 Figure 3: Scatterplots showing the relationships of population-specific $\mathrm{F}_{\text {st }}$ (top panels) and allelic richness (Ar; bottom panel) with

587 connectivity indices based on among-population geographic distance ( $\left.S i_{I B D}\right)$, among-population least cost path through open habitat

$588\left(S i_{L C P}\right)$, and among-population shepherding distance $\left(S i_{I B S}\right)$ for consistently grazed populations $(n=31)$. Each point represents a single

589 consistently grazed population and colour indicates the grazing route each population belongs to (dark grey, route 1; light grey route 2;

590 white, route 3). The size of points represents the population size class. The dashed lines in right panel shows the predicted values from

591 a generalized linear model produced from the program GESTE (top) and from a linear mixed model (bottom). See Table 3 results of

592 model selection on these data. 


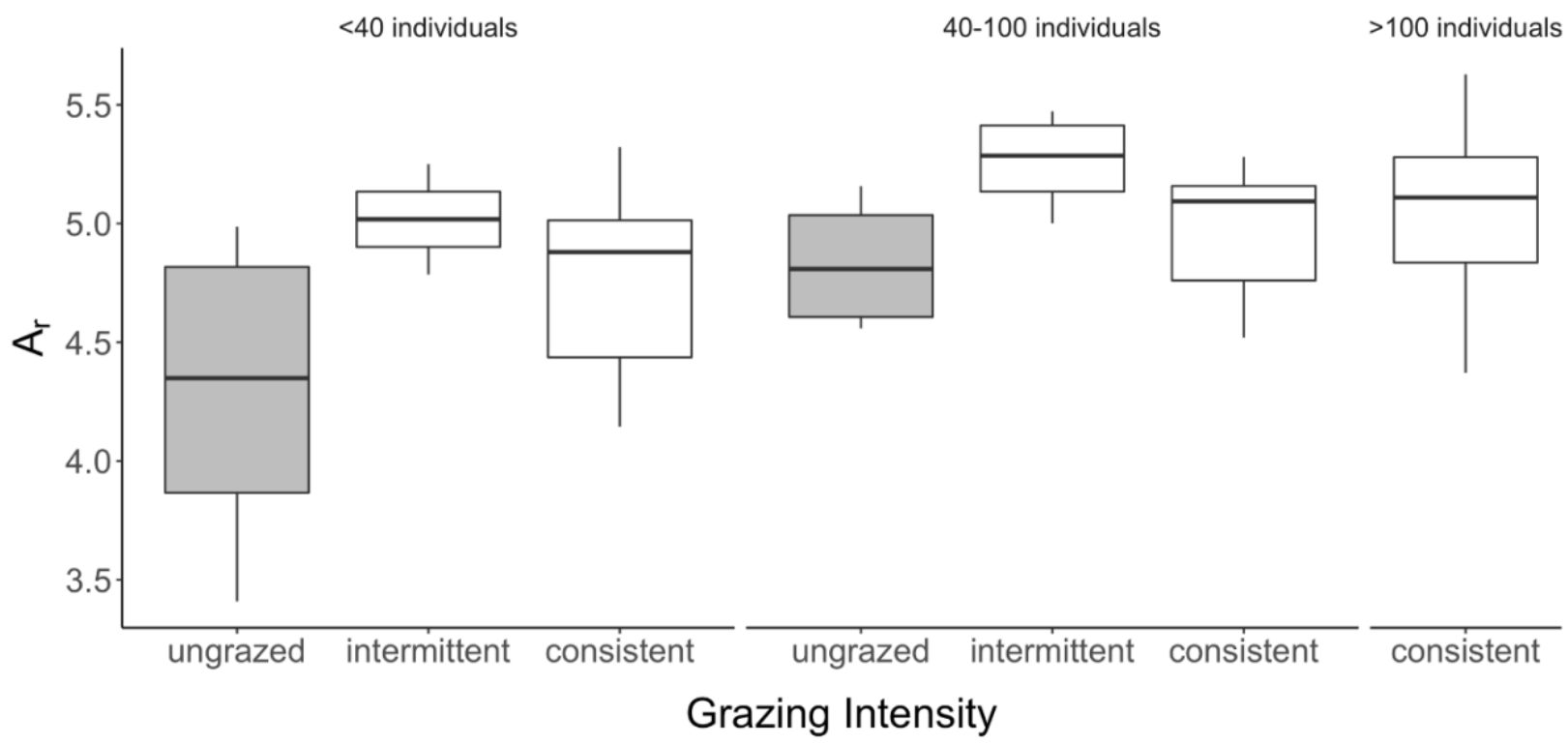

594 Figure 4: Boxplots showing differences in genetic diversity $\left(A_{r}\right)$ among grazing treatment of $P$.

595 vulgaris populations for each population size class (less than 40 individuals, 40-100 individuals, 596 greater than 100 individuals). Boxes with different colours were found to be significantly 597 different in post-hoc tests following a two-way ANOVA. 

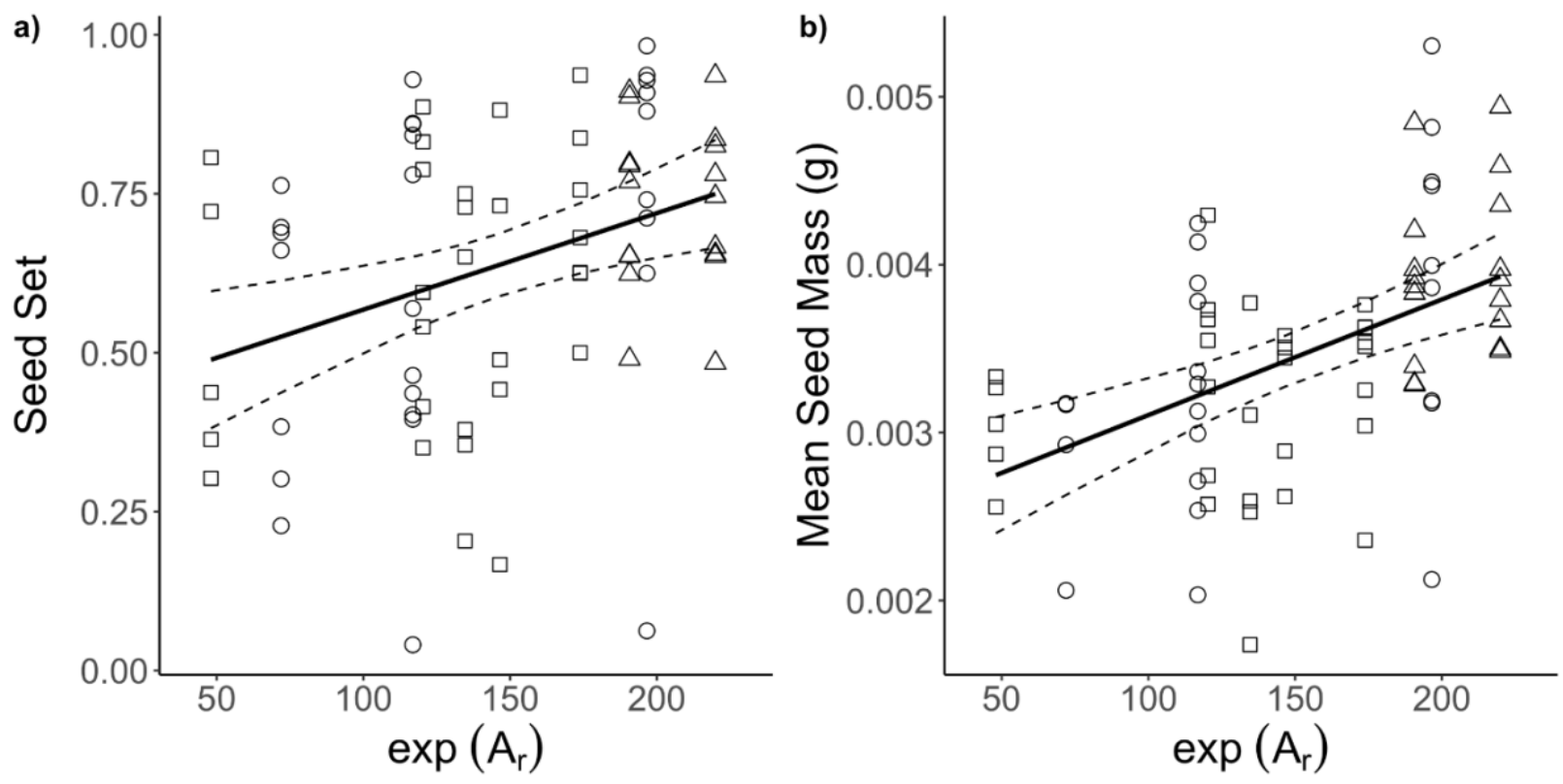

599 Figure 5: Scatterplots showing the relationships between a) seed set and genetic diversity $\left(A_{r}\right)$, 600 and b) mean seed mass and genetic diversity. Each point represents a single individual in one of 601 ten populations, with point shape representing the population grazing treatment (squares = 602 ungrazed; triangles = intermittently grazed; circles = consistently grazed). Solid lines show 603 predicted values for the fixed effect $\left(A_{r}\right)$ from linear mixed effect models controlling for 604 population as a random effect, and dotted lines represent standard error of relationships. Genetic 605 diversity was exponentially transformed to linearize relationships. 
607 Allendorf, F.W., 1986. Genetic drift and the loss of alleles versus heterozygosity. Zoo Biol. 5, 608 181-190.

Armbruster, W.S., Rogers, D.G., 2004. Does pollen competition reduce the cost of inbreeding? Am. J. Bot. 91, 1939-1943.

Auffret, A.G., Rico, Y., Bullock, J.M., Hooftman, D.A., Pakeman, R.J., Soons, M.B., SuárezEsteban, A., Traveset, A., Wagner, H.H., Cousins, S.A., 2017. Plant functional connectivityintegrating landscape structure and effective dispersal. J. Ecol. http://dx.doi.org/10.1111/13652745.12742

Auffret, A.G., Schmucki, R., Reimark, J., Cousins, S.A.O., 2012. Grazing networks provide useful functional connectivity for plants in fragmented systems. J. Veg. Sci. 23, 970-977.

Bacles, C.F.E., Lowe, A.J., Ennos, R.A., 2006. Effective seed dispersal across a fragmented landscape. Science 311, 628-628.

Baguette, M., Blanchet, S., Legrand, D., Stevens, V.M., Turlure, C., 2013. Individual dispersal, landscape connectivity and ecological networks. Biol. Rev. 88, 310-326.

Balkenhol, N., Waits, L.P., Dezzani, R.J., 2009. Statistical approaches in landscape genetics: an evaluation of methods for linking landscape and genetic data. Ecography 32, 818-830.

Bates, D., Maechler, M., Bolker, B., Walker, S. 2015. Fitting linear mixed-effects models using lme4. J. Stat. Softw. 67, 1-48.

Boehmer, H., Janeck, L., Steidler, S., Raab, B., 1990. Verbundsystem Halbtrockenrasen. Trittstein-und Refugialbiotope im östlichen Landkreis Weißenburg-Gunzenhausen. Bayerisches Landesamt für Umweltschutz, Munich, Germany.

Boitani, L., Falcucci, A., Maiorano, L., Rondinini, C., 2007. Ecological networks as conceptual frameworks or operational tools in conservation. Conserv. Biol. 21, 1414-1422.

\section{Breed, M.F., Marklund, M.H.K., Ottewell, K.M., Gardner, M.G., Harris, J.B.C., Lowe, A.J.,} 2012. Pollen diversity matters: revealing the neglected effect of pollen diversity on fitness in fragmented landscapes. Mol. Ecol. 21, 5955-5968.

Bruinderink, G.G., Van Der Sluis, T., Lammertsma, D., Opdam, P., Pouwels, R., 2003. Designing a coherent ecological network for large mammals in northwestern Europe. Conserv. Biol. 17, 549-557.

Butaye, J., Adriaens, D., Honnay, O., 2005. Conservation and restoration of calcareous grasslands: a concise review ofthe effects of fragmentation and management on plant species. 651 
652 Caballero, A., Garcia-Dorado, A., 2013. Allelic diversity and its implications for the rate of 653 adaptation. Genetics 195, 1373.

Calabrese, J.M., Fagan, W.F., 2004. A comparison-shopper's guide to connectivity metrics. Front. Ecol. Environ. 2, 529-536.

Carroll, C., McRae, B.H., Brookes, A., 2012. Use of linkage mapping and centrality analysis across habitat gradients to conserve connectivity of gray wolf populations in western North America. Conserv. Biol. 26, 78-87.

Cushman, S.A., McKelvey, K.S., Schwartz, M.K., 2009. Use of empirically derived sourcedestination models to map regional conservation corridors. Conserv. Biol. 23, 368-376.

de Vere, N., Jongejans, E., Plowman, A., Williams, E., 2009. Population size and habitat quality affect genetic diversity and fitness in the clonal herb Cirsium dissectum. Oecologia 159, 59-68.

DiLeo, M.F., 2016. Conserving connectivity: ecological determinants of gene flow in plants at the landscape scale, In Ecology and Evolutionary Biology. University of Toronto, Toronto.

DiLeo, M.F., Graf, R., Holderegger, R., Rico, Y., Wagner, H.H., 2015. Highly polymorphic microsatellite markers in Pulsatilla vulgaris (Ranunculaceae) using next-generation sequencing. Appl. Plant Sci. 3.

DiLeo, M.F., Siu, J.C., Rhodes, M.K., Lopez-Villalobos, A., Redwine, A., Ksiazek, K., Dyer, R.J., 2014. The gravity of pollination: integrating at-site features into spatial analysis of contemporary pollen movement. Mol. Ecol. 23, 3973-3982.

Dolek, M., Geyer, A., 2002. Conserving biodiversity on calcareous grasslands in the Franconian Jura by grazing: a comprehensive approach. Biol. Conserv. 104, 351-360.

Dyer, R.J., 2014. gstudio: analyses and functions related to the spatial analysis of genetic marker data. $\mathrm{R}$ package, version 1.3.

Dyer, R.J., Chan, D.M., Gardiakos, V.A., Meadows, C.A., 2012. Pollination graphs: quantifying pollen pool covariance networks and the influence of intervening landscape on genetic connectivity in the North American understory tree, Cornus florida L. Landscape Ecol. 27, 239251.

Ellstrand, N.C., 1992. Gene flow by pollen - implications for plant conservation genetics. Oikos $63,77-86$.

Ennos, R.A., 1994. Estimating the relative rates of pollen and seed migration among plantpopulations. Heredity 72, 250-259.

Fay, M.F., Barlow, S.E., 2014. 775. Anemone pulsatilla Ranunculaceae. Curtis's Botanical Magazine 31, 5-16. 
699 Fischer, J., Lindenmayer, D.B., 2007. Landscape modification and habitat fragmentation: a

700 synthesis. Global Ecol. Biogeogr. 16, 265-280.

Fischer, S.F., Poschlod, P., Beinlich, B., 1996. Experimental studies on the dispersal of plants and animals on sheep in calcareous grasslands. J. Appl. Ecol. 33, 1206-1222.

Foll, M., Gaggiotti, O., 2006. Identifying the environmental factors that determine the genetic structure of populations. Genetics 174, 875-891.

Frankham, R., 2005. Genetics and extinction. Biological Conservation 126, 131-140.

Gathmann, A., Tscharntke, T., 2002. Foraging ranges of solitary bees. J. Anim. Ecol. 71, 757764.

Gilbert-Norton, L., Wilson, R., Stevens, J.R., Beard, K.H., 2010. A meta-analytic review of corridor effectiveness. Conserv. Biol. 24, 660-668.

Hanski, I., 1994. A practical model of metapopulation dynamics. J. Anim. Ecol. 63, 151-162.

Hensen, I., Oberprieler, C., Wesche, K., 2005. Genetic structure, population size, and seed production of Pulsatilla vulgaris Mill. (Ranunculaceae) in Central Germany. Flora 200, 3-14.

Hughes, A.R., Inouye, B.D., Johnson, M.T.J., Underwood, N., Vellend, M., 2008. Ecological consequences of genetic diversity. Ecol. Lett. 11, 609-623.

Jackson, N.D., Fahrig, L., 2014. Landscape context affects genetic diversity at a much larger spatial extent than population abundance. Ecology 95, 871-881.

Jacquemyn, H., Brys, R., Hermy, M., 2003. Short-term effects of different management regimes on the response of calcareous grassland vegetation to increased nitrogen. Biol. Conserv. 111, 137-147.

Johnson, M.T.J., Lajeunesse, M.J., Agrawal, A.A., 2006. Additive and interactive effects of plant genotypic diversity on arthropod communities and plant fitness. Ecol. Lett. 9, 24-34.

Kamm, U., Gugerli, F., Rotach, P., Edwards, P., Holderegger, R., 2010. Open areas in a

Kormann, U., Roesch, V., Batary, P., Tscharntke, T., Orci, K.M., Samu, F., Scherber, C., 2015. Local and landscape management drive trait-mediated biodiversity of nine taxa on small grassland fragments. Divers. Distrib. 21, 1204-1217.

Kratochwil, A., 1988. The pollination strategy of Pulsatilla vulgaris mill. Flora 181, 261-324. 
Lamy, T., Jarne, P., Laroche, F., Pointier, J.P., Huth, G., Segard, A., David, P., 2013. Variation in habitat connectivity generates positive correlations between species and genetic diversity in a metacommunity. Mol. Ecol. 22, 4445-4456.

Lande, R., 1988. Genetics and demography in biological conservation. Science 241, 1455-1460.

Landguth, E.L., Muhlfeld, C.C., Waples, R.S., Jones, L., Lowe, W.H., Whited, D., Lucotch, J., Neville, H., Luikart, G., 2014. Combining demographic and genetic factors to assess population vulnerability in stream species. Ecol. Appl. 24, 1505-1524.

Leimu, R., Mutikainen, P., Koricheva, J., Fischer, M., 2006. How general are positive relationships between plant population size, fitness and genetic variation? J. Ecol. 94, 942-952.

Lennartsson, T., Wissman, J., Bergström, H.-M., 2012. The effect of timing of grassland management on plant reproduction. Int. J. Ecol. 2012.

Luque, G.M., Vayssade, C., Facon, B., Guillemaud, T., Courchamp, F., Fauvergue, X., 2016.

The genetic Allee effect: a unified framework for the genetics and demography of small populations. Ecosphere 7.

Luque, S., Saura, S., Fortin, M.-J., 2012. Landscape connectivity analysis for conservation: insights from combining new methods with ecological and genetic data. Landscape Ecol. 27, 153-157.

Maiorano, L., Amori, G., Montemaggiori, A., Rondinini, C., Santini, L., Saura, S., Boitani, L., 2015. On how much biodiversity is covered in Europe by national protected areas and by the Natura 2000 network: insights from terrestrial vertebrates. Conserv. Biol. 29, 986-995.

Manzano, P., Malo, J.E., 2006. Extreme long-distance seed dispersal via sheep. Front. Ecol. Environ. 4, 244-248.

Maruyama, T., Fuerst, P.A., 1985. Population bottlenecks and nonequilibrium models in population-genetics. II. Number of alleles in a small population that was formed by a recent bottleneck. Genetics 111, 675-689.

McNeely, J.A., Miller, K.R., Reid, W.V., Mittermeier, R.A., Werner, T.B., 1990. Conserving the world's biological diversity. International Union for conservation of nature and natural resources.

Melles, S., Fortin, M.-J., Badzinski, D., Lindsay, K., 2012. Relative importance of nesting habitat and measures of connectivity in predicting the occurrence of a forest songbird in fragmented landscapes. Avian Conserv. Ecol. 7.

Mijangos, J.L., Pacioni, C., Spencer, P.B.S., Craig, M.D., 2015. Contribution of genetics to ecological restoration. Mol. Ecol. 24, 22-37. 
Nakagawa, S., Schielzeth, H., 2013. A general and simple method for obtaining $\mathrm{R}^{2}$ from generalized linear mixed-effects models. Methods Ecol. Evol. 4, 133-142.

Piqueray, J., Saad, L., Bizoux, J.P., Mahy, G., 2013. Why some species cannot colonise restored

R Core Team., 2015: R: a language and environment for statistical computing. In: R Foundation for Statistical Computing, Vienna, Austria, https://www.R-project.org.

Raymond, M., Rousset, F., 1995. Genepop (version-1.2) - population-genetics software for exact tests and ecumenicism. J. Hered. 86, 248-249.

Reed, D.H., 2005. Relationship between population size and fitness. Conserv. Biol. 19, 563-568.

Reed, D.H., Frankham, R., 2003. Correlation between fitness and genetic diversity. Conserv. Biol. 17, 230-237.

Rico, Y., Boehmer, H.J., Wagner, H.H., 2012. Determinants of actual functional connectivity for calcareous grassland communities linked by rotational sheep grazing. Landscape Ecol. 27, 199209.

Rico, Y., Boehmer, H.J., Wagner, H.H., 2014a. Effect of rotational shepherding on demographic and genetic connectivity of calcareous grassland plants. Conserv. Biol. 28, 467-477.

Rico, Y., Holderegger, R., Boehmer, H.J., Wagner, H.H., 2014b. Directed dispersal by rotational shepherding supports landscape genetic connectivity in a calcareous grassland plant. Mol. Ecol. $23,832-842$.

Takkis, K., Partel, M., Saar, L., Helm, A., 2013. Extinction debt in a common grassland species: immediate and delayed responses of plant and population fitness. Plant Ecol. 214, 953-963.

van Etten, J. 2017. R Package gdistance: Distances and routes on geographical grids. J. Stat. Softw. 76, 1-21.

Vilas, A., Perez-Figueroa, A., Quesada, H., Caballero, A., 2015. Allelic diversity for neutral markers retains a higher adaptive potential for quantitative traits than expected heterozygosity. Mol. Ecol. 24, 4419-4432.

Wagner, H.H., Rico, Y., Lehnert, H., Boehmer, H.J., 2013. Process-based long-term evaluation of an ecological network of calcareous grasslands connected by sheep herding. Ecography 36, 374-382.

WallisDeVries, M.F., Poschlod, P., Willems, J.H., 2002. Challenges for the conservation of calcareous grasslands in northwestern Europe: integrating the requirements of flora and fauna. Biol. Conserv. 104, 265-273. 
834 Wells, T.C.E., Barling, D.M., 1971. Biological flora of british-isles - Pulsatilla vulgaris mill 835 (Anemone pulsatilla L). J. Ecol. 59, 275-292.

837 Whitelaw, G.S., Eagles, P.F.J., 2007. Planning for long, wide conservation corridors on private 838 lands in the Oak Ridges Moraine, Ontario, Canada. Conserv. Biol. 21, 675-683.

840 Wolfe, K.H., 2001. Yesterday's polyploids and the mystery of diploidization. Nat. Rev. Genet. 2, 841 333-341.

842

843 Yasui, Y., 1998. The 'genetic benefits' of female multiple mating reconsidered. Trends Ecol.

844 Evol. 13, 246-250.

845

846 Zurbuchen, A., Landert, L., Klaiber, J., Mueller, A., Hein, S., Dorn, S., 2010. Maximum foraging 847 ranges in solitary bees: only few individuals have the capability to cover long foraging distances. 848 Biol. Conserv. 143, 669-676. 